Erratum

\title{
Relativistic Multiple Scattering Theory of Electrons by Ferromagnets
}

\author{
R. Feder and F. Rosicky \\ Theoretische Festkörperphysik, FB 10, Universität Duisburg GH, Duisburg, \\ Federal Republic of Germany \\ B. Ackermann \\ Institut für Festkörperforschung, KFA Jülich, Federal Republic of Germany \\ Z. Phys. B - Condensed Matter 52, 31-36 (1983)
}

In equation (7a) the central line should contain $\left\langle\chi_{-\kappa}^{\mu}\right|$ (instead of $\left.\left\langle\chi_{k}^{\mu}\right|\right)$, and in equation $\left(15^{\prime} c\right)$ the third line should contain $\left(f^{1} \tilde{f}^{2}-\tilde{f}^{1} f^{2}\right)$ (instead of $\left(f^{1} \tilde{f}^{2} f^{2}\right)$ ).

\author{
R. Feder \\ F. Rosicky \\ Theoretische Festkörperphysik \\ Fachbereich 10 \\ Universität Duisburg $\mathrm{GH}$ \\ Bismarckstrasse 81 \\ D-4100 Duisburg \\ Federal Republic of Germany
}

\author{
B. Ackermann \\ Institut für Festkörperforschung \\ Kernforschungsanlage Jülich GmbH \\ Postfach 1913 \\ D-5170 Jülich 1 \\ Federal Republic of Germany
}

